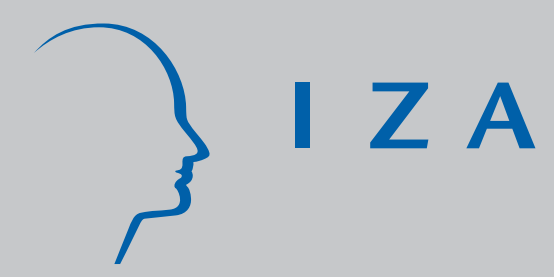

IZADP No. 1660

Regional Dependencies in J ob Creation: An Efficiency Analysis for Western Germany

René Fahr Uwe Sunde

J uly 2005 


\title{
Regional Dependencies in Job Creation: An Efficiency Analysis for Western Germany
}

\author{
René Fahr \\ University of Cologne \\ and IZA Bonn \\ Uwe Sunde \\ IZA Bonn
}

Discussion Paper No. 1660

July 2005

IZA

P.O. Box 7240

53072 Bonn

Germany

Phone: +49-228-3894-0

Fax: +49-228-3894-180

Email: iza@iza.org

\begin{abstract}
Any opinions expressed here are those of the author(s) and not those of the institute. Research disseminated by IZA may include views on policy, but the institute itself takes no institutional policy positions.

The Institute for the Study of Labor (IZA) in Bonn is a local and virtual international research center and a place of communication between science, politics and business. IZA is an independent nonprofit company supported by Deutsche Post World Net. The center is associated with the University of Bonn and offers a stimulating research environment through its research networks, research support, and visitors and doctoral programs. IZA engages in (i) original and internationally competitive research in all fields of labor economics, (ii) development of policy concepts, and (iii) dissemination of research results and concepts to the interested public.
\end{abstract}

IZA Discussion Papers often represent preliminary work and are circulated to encourage discussion. Citation of such a paper should account for its provisional character. A revised version may be available directly from the author. 
IZA Discussion Paper No. 1660

July 2005

\section{ABSTRACT}

\section{Regional Dependencies in Job Creation: An Efficiency Analysis for Western Germany*}

This paper investigates the efficiency of the matching process between job seekers and vacancy posting firms in West-Germany, using variation across labor market regions and across time. The results of a stochastic frontier analysis shed new light on extent and regional differences of search frictions, on potential determinants of frictional inefficiencies and on the consequences of German reunification for the matching process. The paper also presents novel evidence on the complex interactions between spatial contingencies among regional labor markets: matching efficiency decreases with spatial autocorrelation in hiring, implying indirect evidence for crowding externalities.

JEL Classification: J61, J64, J21, R12

Keywords: regional unemployment, stochastic frontier, matching function, spatial autocorrelation

Corresponding author:

René Fahr

Department of Business Administration

University of Cologne

Herbert-Lewin-Str. 2

D-50931 Cologne

Germany

Email: rene.fahr@uni-koeln.de

\footnotetext{
"Substantially revised and rewritten version of "Estimations of Occupational and Regional Matching Efficiencies Using Stochastic Production Frontier Models" by René Fahr and Uwe Sunde, IZA Discussion Paper No. 552, August 2002.
} 


\section{Introduction}

Most European labor markets are characterized by high and persistent levels of unemployment. Many different proposals of how legislation and governments could and should actively intervene have been publicly discussed. In several countries, including Germany, measures have been taken to particularly reduce the frictions associated with the creation of new jobs and to improve the efficiency of the matching process between the unemployed and firms that try to fill vacancies. Empirical evidence about the determinants of the efficiency of the matching process, about the structure of the underlying search frictions, and about the matching process in general is still scarce, however, despite the fact that theoretical matching models of unemployment are widespread nowadays and have been used frequently to analyze many different aspects of frictional labor markets. Only recently have researchers taken the matching function, which constitutes the core element to model frictions in these models, to the data, see the survey by Petrongolo and Pissarides (2001). The matching function describes the inflow into new jobs as function of the numbers of job searchers and vacant positions in a parsimonious, but nevertheless empirically relevant way, as the recent contributions show.

This paper contributes to the empirical literature on labor market frictions and the job creation process in several ways. While matching functions have been estimated before using German data, see e.g. Gross (1997), Entorf (1998), and Fahr and Sunde (2004), this is the first study that offers a detailed analysis of the efficiency of the matching process in Germany. Following Warren (1991), we apply a stochastic production frontier approach 
to model the matching process. Moreover, while Warren (1991) estimates stochastic matching frontiers for the U.S. manufacturing sector using only time series variation in the data, we use panel data that allow us to also exploit regional variation. Only two other recent contributions by Ilmakunnas and Pesola (2003) and Ibourk, Maillard, Perelman, and Sneessens (2004) also utilize spatial variation in data from Finland and France, respectively, in a stochastic frontier framework in the matching context. ${ }^{1}$ The presented methodology is useful to investigate inefficiencies in the creation of new jobs, since it allows to simultaneously estimate the parameters of the stochastic production frontier and the extent and determinants of the inefficiencies involved in the job creation process. The longitudinal data additionally allow to identify variations in the efficiency of the matching process over time. Since we use data for the period 1980-1997, our analysis can therefore shed some new light on the consequences of German reunification on the matching process, and its efficiency in particular. This paper also conducts the first in-depth analysis of spatial correlation patterns in the job creation process. Moreover, this is the first study that links estimates of the matching efficiency of single regional labor markets to particular spatial characteristics of these labor markets. More specifically, we investigate how spatial correlation and spatial dependencies in the flows of newly created job matches affect the efficiency of the matching process on the regional level.

Our results for the parameters of the matching technology are very sim-

\footnotetext{
${ }^{1}$ Another recent stochastic frontier analysis using data for Italy and distinguishing between 3 major regions, North, Center and South, is the study by Destefanis and Fonseca (2004). Earlier contributions using regional variation to estimate the parameters of the aggregate matching function, are Gorter and Van Ours (1994) and Burgess and Profit (2001), among others.
} 
ilar to previous studies using regionally disaggregated data and indicate a relatively larger weight of job seekers in the matching process. The explicit consideration of inefficiencies explains about three quarters of the total variation, suggesting the importance of taking inefficiencies into account. We find large variation in the efficiency of the matching process across regions, with the bulk of regions displaying a degree of efficiency of between 50 and 80 percent. Inefficiencies seem to have declined over the observation period, in particular with German reunification. The regional pattern of matching efficiency, however, is very stable over time.

Using the same data set, we investigate how job creation, i.e. flows of matches, is correlated across regions that are spatially contiguous. The resulting pattern of spatial autocorrelation in regional matching also shows considerable regional variation, which is fairly stable over time. Some regions, clusters, exhibit significantly positive spatial autocorrelation in matches, and other regions, hot spots, exhibit negative autocorrelation patterns. We investigate the variation in matching efficiency across regions by relating the efficiency of the regional matching process to spatial correlation in hiring flows. We find evidence for crowding externalities that lead to search frictions and lower matching efficiency in hot spots as well as in clusters. When looking at the entire sample, the effects are more pronounced in clusters than in hot spots. Interestingly, when splitting the sample into pre and post reunification period, the correlation is stronger for hot spots than for clusters before reunification. After reunification, the opposite is true, with the effect slightly lower for hot spots, but significantly larger for clusters in absolute terms.

The structure of the paper is as follows. In the next section we model 
regional job creation in a stochastic frontier framework, describe the data used in this paper and present empirical results. A detailed analysis of spatial dependencies in the matching process and their relation to differences in regional matching efficiencies follows in section 3. Section 4 concludes.

\section{Efficiency Analysis of the Matching Process}

Several recent empirical studies investigate the variation in the matching process across regions, see Petrongolo and Pissarides (2001) for an overview. However, evidence about the efficiency of the matching process and its determinants, in particular in the regional context is scarce. In this section, we analyze the the efficiency of the matching process in a stochastic frontier framework following the approach proposed by Battese and Coelli (1995).

\subsection{The Stochastic Frontier Approach}

Following the methodology proposed in Battese and Coelli (1995), we explicitly model efficiency in the matching process. Consider the following specification modelling the flow of new hires $m_{i t}$ in a given region $i$ between date $t$ and $t+1$ as a function of the stocks of unemployed job searchers $U_{i t}$ and vacancies $V_{i t}$ at the beginning of the observation period, i.e. at date $t$ :

$$
m_{i t}=A U_{i t}^{\alpha} V_{i t}^{\beta} e^{\varepsilon_{i t}+R_{i t}},
$$

where $A$ is a constant, $\varepsilon_{i t}$ is an i.i.d. $N\left(0, \sigma_{\varepsilon}^{2}\right)$ error, and $R_{i t}$ represents technical efficiency of the matching process. The efficiency term $R_{i t}$ can itself be a function of a set of explanatory variables $Z$ :

$$
R_{i t}=Z_{i t} \delta+\omega_{i t}
$$


$Z_{i t}$ is a $(1 \times k)$ vector (of realizations of) a set of $k$ explanatory variables, and the process is described by a $(k \times 1)$ vector of unknown coefficients $\delta$. The first element of the $Z$-vector, $Z_{0}$, is a constant. Moreover, the composition of the regional labor force with respect to age and educational background seems to be a relevant factor for explaining matching efficiencies. Therefore, we add the shares of workforce younger than 25 years and older than 50 years in the respective region, as well as shares of workers with low education and high education. Finally, including the level of unemployment and the ratio of vacancies to unemployed in the respective region measuring labor market tightness as explanatory variables of inefficiency allows to control for search intensity of and competition among the seeker pools on both sides of the labor market. Furthermore, $Z$ contains a deterministic time trend and an indicator variable for the post-reunification period. ${ }^{2}$ The random variable $\omega_{i t}$ is a truncation of the normal distribution with zero mean and variance $\sigma_{\omega}^{2}$. The truncation point for $R_{i t}$ is $-Z_{i t}$, i.e. $\omega_{i t} \leq-Z_{i t} \delta$, so $R_{i t}$ is a non-negative truncation of the normal distribution with $N\left(0, \sigma_{\omega}^{2}\right)$. The share of the total variance of the process that can be explained by the efficiency term, denoted as $\gamma$, is a measure of the importance of inefficiencies, and indicates the relevance of explicitly analyzing the efficiency of the matching process. All coefficients are estimated jointly by maximizing the log-likelihood function of the model. ${ }^{3}$ A prediction of the matching efficiency of a particular regional labor market can be obtained using the respective coefficient estimates together with the respective observations for

\footnotetext{
${ }^{2}$ We alternatively experimented with year dummies, see discussion below.

${ }^{3}$ See Battese and Coelli (1995) for details of the model and the derivation of the likelihood function.
} 
the $Z$-variables in equation (2).

\subsection{Data issues}

The data used for the analysis below are yearly data on unemployment, vacancies and hirings for the years 1980 until 1997 for 117 regions in Western Germany. The data for stocks of unemployed and vacancies are taken from official labor statistics and available for so called Employment Office Districts. The flow data for new matches are constructed from hiring data measured on the individual level which stem from an anonymized representative $1 \%$ sample of German social security records provided by the German Federal Institute for Employment Research (IAB). The database is supplemented by data on unemployment benefits recipients and by establishment information (see Bender, Haas, and Klose (2000) for details). In contrast to the measure of matches used by Ilmakunnas and Pesola (2003), which is constructed from unemployment outflows and cannot distinguish between outflows into employment from outflows into other states, we use a measure of all hires that constitute new employment relationships in a given region. ${ }^{4}$ By that, our measure of hires includes all hires of male and female job searchers of all age groups irrespective of their former job status, but records regional origin. Hiring flows are the cumulative flows between October 1st of a year $t$ and September 30th of the following year $t+1$ for a certain region. The stocks of unemployed and vacancies corresponding to these hiring flows are taken as of September 30th of the year before the flows are constructed (i.e. $t$ ). Regions are identified by locations of employers and

\footnotetext{
${ }^{4}$ Similarly, Ibourk et al. (2004) use also a measure of unemployment-to-job transitions of workers in region $i$. However, their measure cannot identify regional transitions.
} 
correspond to labor market districts. The definition is provided by the Federal Office of Building and Regional Planning, and accounts for a scientific analysis of commuting flows as well as some political constraints. In particular, the definition of labor market districts is designed to capture commuting areas and minimize commuting flows across districts. We merge the hirings data and the stock data to the respective coarser region definition, which is in most of the cases the one from official labor statistics defining regions as Employment Office Districts. A list with the labor market regions used in the empirical analysis, as well as a map indicating their location, are contained in the Appendix. While the data source which we use to construct our measure of hires is very precise in reporting individuals employment history, the information on the socio-economic background of individuals is sparse. Therefore, we are only able to distinguish three educational levels. We define individuals as having low education if they neither successfully completed high school (Abitur), nor obtained a vocational degree. Individuals have high education, if they hold a degree from a university or an applied university (Fachhochschule). Moreover, the individual data contain an age variable, which allows us to construct the shares of persons above 65 years and below 25 years in the workforce on basis of the individual social security records.

In order to be able to calculate statistics to measure spatial autocorrelation that will be used below, we need to construct spatially lagged counterparts of the key variables, stocks and flows, that we use. We do this by constructing a spatial weights matrix indicating the contiguity of regions. Since the data we use consist of cells of 117 West-German labor market regions, we define contiguity between two regions as the regions sharing a 
common border. The corresponding spatial weights matrix $W$ is therefore a symmetric $117 \times 117$ matrix with entries 0 and 1 , where 1 indicates contiguity. ${ }^{5}$

\subsection{The Matching Efficiency of Regional Labor Markets}

The results obtained by applying the stochastic frontier analysis to our WestGerman data are displayed in Table 1. Both specifications are identical apart from the dynamic specification of the efficiency term. In specification (1), the efficiency term contains linear and quadratic time trends and a dummy for the post-reunification period, while specification (2) contains a linear time trend, a post-reunification dummy and an interaction of the trend and the post-reunification dummy.

Consider first the structural part of the matching function. The flow of new matches is specified as the total inflows into new jobs, as is done in most of the empirical matching literature. ${ }^{6}$ The specification contains the $(\log )$ stock of vacancies, and the (log) stock of unemployed job seekers for a given region. Given the data structure, the stock of unemployed job seekers that is relevant for generating new matches with vacancies posted by firms in that region is composed of three components: unemployed from that region, $U$, unemployed from neighboring regions $W U$, and unemployed

\footnotetext{
${ }^{5}$ The entries on the main diagonal of $W$ are zeros, since a region cannot be contiguous to itself.

${ }^{6}$ We have also experimented with different concepts of flows, such as only considering matches involving workers that were not employed previous to the observed match. While leading to qualitatively similar results, we concentrate attention on all matches for reason of comparability with the empirical matching literature, and the other studies of matching efficiency using regionally disaggregated data.
} 
from regions that are further away, $\underline{W U} .^{7}$ The specification only uses vacancies in the respective region for which the flows are measured, i.e. does not control for vacancies in neighboring or other regions, because the definition of regions refers to the location of employers. Adding other than the local vacancies would therefore constitute a misspecification of the matching model. ${ }^{8}$ Our results are broadly in line with previous results estimating empirical matching functions, as discussed in Broersma and Van Ours (1999) and Petrongolo and Pissarides (2001). In particular, the more vacancies are posted in a given region, the more matches are created. The same holds for the stocks of unemployed from that region or from non-neighboring regions. The negative coefficient for unemployed from neighboring regions implies a non-trivial pattern of contingencies across regions. While not the focus of this paper, this negative impact of neighboring unemployed job seekers indicates potential competition for jobs between different groups of unemployed, and also reflects business cycle effects. ${ }^{9}$ The coefficient estimates are virtually identical in both specifications, implying a relatively larger importance of job seekers for the generation of new matches. Also, they are comparable to the findings in previous contributions, see the overview contained in Table 1 of Broersma and Van Ours (1999). The estimation results of Ilmakunnas and Pesola (2003) and Ibourk et al. (2004) for Finnish and French regional

\footnotetext{
${ }^{7}$ Regions are neighboring if they share a common border, as indicated in the contiguity matrix $W . W U_{t}$ and $\underline{W} U_{t}$ are the inner products of the row of the contiguity matrix $W$ corresponding to a given region with the vector of the unemployment stocks for a given year $t$.

${ }^{8}$ Ilmakunnas and Pesola (2003) and Ibourk et al. (2004) do not account for regional dependencies at all in their specifications of the matching technology.

${ }^{9}$ Higher levels of unemployment in other regions are proxy for a contraction, which implies fewer matches than a boom.
} 
data, respectively, are roughly comparable. They both find a slightly higher coefficient for unemployed, and a slightly lower coefficient for vacancies in their preferred specification. ${ }^{10}$

\section{$<$ INSERT TABLE 1 ABOUT HERE $>$}

Now turn to the efficiency results displayed in Table 1. The matching process seems significantly more efficient in regions with a larger fraction of participants in the labor market younger than 25 years, and less efficient, but insignificantly, in regions with a large fraction of workers older than 50 years. These results are in line with earlier findings by Ibourk et al. (2004), and indicate different search effectivity of different age groups, resulting from the use of more modern search technologies, different search intensities, lower incentives to search for elderly due to institutional factors, or discrimination of firms in favor of younger workers. More interestingly, the regional matching process is significantly more efficient the higher the fractions of high and low educated as compared to the fraction of workers with intermediate levels of education. A potential reason for the higher efficiency of regions with many high skilled workers is obvious: better educated workers are more able to find new employment because they use better search strategies, and can adapt better to different environments. The higher efficiency of regions

\footnotetext{
${ }^{10}$ Ibourk et al. (2004) estimate a flexible translog form of the matching function, which delivers results that are not directly comparable. Similar to Ilmakunnas and Pesola (2003), we decided to estimate a standard specification of the matching function for comparability with other empirical studies, and since we are mainly interested in the analysis of the efficiency term. Experiments using a translog specification did lead to somewhat different estimates for the structural elasticities, but did not alter the results for the efficiency term substantially. Since our analysis is mainly concerned with the latter, we chose the simplest and most widespread specification.
} 
with many workers with little education is likely to be a result of the lower requirements firms have for workers doing particular tasks. Screening of applicants for jobs aimed at low qualified workers is not complicated, so the job creation process seems to exhibit less frictions in this segment of the labor market. Search intensity of firms and competition among firms for applicants, as measured by labor market tightness, significantly increases the matching efficiency, as does search intensity and competition among job seekers measured by the level of local unemployment.

In the specific context of Germany, whose reunification falls in the middle of the observation window of the data used here, the dynamic structure of matching efficiency is of particular interest. Specification (1) reveals a positive trend in matching efficiency, whose impact becomes weaker along the observation period, as indicated by the negative quadratic term. Interestingly, re-unification had a significantly positive impact on the efficiency of the matching process. Specification (2) gives a similar impression. While the linear time trend is negative, but only about a third of the trend in the other specification, the reunification dummy shifts the matching process closer to the efficient frontier. An interaction term between trend and reunification indicator is negative but insignificant. Nevertheless, this interaction term indicates some deterioration of matching efficiency after the reunification took place. ${ }^{11}$ Both specifications also differ not much in their explanatory

\footnotetext{
${ }^{11}$ Decreasing trends in matching efficiency have been found in earlier studies for Germany and other countries, see e.g. Ilmakunnas and Pesola (2003) and Fahr and Sunde (2002). In contrast to Ilmakunnas and Pesola (2003), however, we refrain from inserting dynamic components in the structural part of the matching function, since with dynamic elements in both, the structural and the efficiency component, identification becomes difficult and entirely relies on distributional assumptions, see Battese and Coelli (1995) and
} 
power, as indicated particularly by the share of the total variance accounted for by the efficiency term, $\gamma$, and both specifications are superior to simple OLS estimations of empirical matching functions for West-German labor market regions. ${ }^{12}$

As noted before, these coefficient estimates can be used to predict the matching efficiency of a particular region. This is done for every region and year. Regions can then be ranked with respect to their estimated matching efficiency. The resulting rankings of the five regions with the highest and the five with the lowest matching average efficiencies over the observation period for specification (1) in Table 1 are presented in Table 2. Apparently, large metropolitan regions such as Munich, Düsseldorf and Frankfurt, exhibit particularly high matching efficiencies over the entire observation period 1980-1997. When computing averages over the pre-reunification and post-reunification periods separately, it turns out that this result is mainly driven by the high efficiencies these metropolitan areas display after the reunification. The most consistent result is for Munich, which operates close to the efficiency frontier throughout the observed period. In contrast, mainly rural and thinly populated regions in Northern Germany consistently show the relatively lowest matching efficiencies in our sample. The frequency distribution of average matching efficiencies over the entire sample period is Karagiannis, Midmore, and Tzouvelekas (2002) for a more detailed discussion of this issue. Experiments with dynamic elements in both technology and efficiency components revealed similar results for the efficiency component.

${ }^{12}$ We also conducted fully flexible estimations of the dynamics of the efficiency term by including a full set of year dummies instead of trend and reunification dummy. The results, which are available on request, are similar, with significantly higher efficiency estimates in the second half of the observation period. 
depicted in Figure 1. ${ }^{13}$ The figure illustrates that the bulk of regions exhibits matching efficiencies of around 60 to 80 percent, or, conversely, inefficiencies of 20 to 40 percent. Only very few regions achieve efficiency estimates of more than 90 or less than 45 percent. This begs the question what drives the relative position of a given region in this distribution, and the apparent stability of the relative position in the distribution implied by the results

just mentioned. Apart from the explanatory variables already included in the efficiency component, an obvious candidate to affect matching outcomes and thus the efficiency of the matching process that has not been accounted so far is spatial correlation in the job creation process. Spatial dependencies in matching of neighboring regions, for example, could reflect crowding externalities, spatial peculiarities, or directed search behavior, all of which could influence the efficiency of the matching process and the speed at which job seekers and vacancies find each other. The following section attempts to shed some light on this question.

$<$ INSERT TABLE 2 ABOUT HERE $>$ $<$ INSERT FIGURE 1 ABOUT HERE $>$

\section{Spatial Dependencies and the Efficiency of Re- gional Matching}

This section takes a closer look on spatial dependencies in West-German labor markets. The regional differences in the efficiency of the matching process, together with the persistence of these differences over time suggests

\footnotetext{
${ }^{13}$ Distributions of the predicted efficiencies averaged for pre- and post-reunification phases separately are very similar and available upon request.
} 
that spatial correlations in the matching process could potentially explain part of the variation.

\subsection{Spatial Autocorrelation}

We begin by testing whether the variable of primary interest in the context of empirical labor market matching exhibits spatial autocorrelation. Spatial autocorrelation means that the spatial distribution of new successful matches during a certain defined period of time (in our case a year) exhibits a systematic pattern. In other words, if new matches are positively spatially autocorrelated, a high job creation activity in a certain region is associated with high job creation in nearby regions.

Strictly speaking, what is required is a test for local spatial autocorrelation in the data, which measures, for each region, the correlation pattern in matching with neighboring regions. Therefore, in the following we employ the Local Moran's I Statistic:

$$
I_{i}=\frac{\left(m_{i}-\bar{m}\right)}{\sum_{k=1}^{N} \frac{\left(m_{k}-\bar{m}\right)^{2}}{N}} \sum_{j=1}^{N} w_{i j}\left(m_{j}-\bar{m}\right),
$$

where $m_{i}$ is the variable of interest, namely the flow of matches in the particular region $i$ during a given year, $\bar{m}$ denotes the (cross-sectional) mean of $m$ for the given year, and $w_{i j}$ is the element of the spatial weights matrix $W$ corresponding to the location pair $(i, j) .{ }^{14}$ Under the null hypothesis of no spatial autocorrelation, the expected value of $I_{i}$ is $E\left(I_{i}\right)=\frac{-\sum_{j=1}^{N} w_{i j}}{N-1}$. If $I_{i}$ is

\footnotetext{
${ }^{14}$ See Anselin (1995) for a detailed discussion of this statistic and its properties. Note that a global measure, like the Global Moran's I would not deliver regional variation in the correlation patterns, and therefore not allow to use the measure to test for correlations with regional matching efficiency estimates.
} 
larger than this, then flows $m$ have a distribution characterized by positive spatial autocorrelation, in the sense that high values of $m$ are associated with high realizations of $m$ in spatially contiguous regions. The opposite holds for values of $I_{i}$ smaller than this value, indicating negative spatial autocorrelation. Inference is based on $x_{I}=\frac{I-E(I)}{s d(I)}$, where $s d(I)$ is the standard deviation of $I$.

Testing for local spatial autocorrelation in the flow of matches, it turns out that spatial patterns exhibit substantial heterogeneity across regions. Moreover, this heterogeneity is fairly stable over time, in the sense that regions with strong evidence for spatial autocorrelation at the beginning of the observation period (early 1980s) are also the regions for which the null is rejected strongly at the end of the observation period (mid/late 1990s). Table 3 contains the ten regions with the highest test scores for positive and negative spatial autocorrelation, respectively, as measured by Local Moran's $I$ averaged over the years 1980 to 1997. In the following we denote the group of regions that exhibit significantly positive spatial autocorrelation in their hiring process as clusters, and call those regions whose job creation is significantly negatively autocorrelated hot spots. Obviously, the Ruhr area around the cities Düsseldorf, Essen and Gelsenkirchen represents a huge common labor market, characterized by strong positive spatial autocorrelation. Also regions in the North and North-West exhibit strong positive local spatial autocorrelation in the matching process. On the other hand, agglomeration areas surrounded by less densely populated, rural regions, like Hamburg, Frankfurt, Stuttgart and Munich constitute hot spots that attract many workers from surrounding areas during booms and set free many workers to surrounding areas during recessions. Already from comparing the spatial 
correlation results for matches in Table 3 with the results for matching efficiency in Table 2, it seems that efficiency and spatial correlation structure of matches exhibit similarities. We now turn to analyze this relationship in more detail.

\section{$<$ INSERT TABLE 3 ABOUT HERE $>$ $<$ INSERT TABLE 4 ABOUT HERE $>$}

\subsection{Spatial Dependencies and Matching Efficiency}

The question that arises from the previous results is whether and how geographical labor market characteristics in terms of certain spatial correlation patterns in job creation affect the efficiency of the job creation process. To address this question, we regress the estimated efficiency of the matching process in a given region in a given year on the spatial autocorrelation pattern in form of the value of the Local Moran's $I$ for the respective period in the respective region. Spatial autocorrelation patterns are not used as determinants of the efficiency component in the frontier analysis for several reasons. First, adding Local Moran's I coefficients as explanatory variables for the efficiency of the matching process would lead to endogeneity problems, because the autocorrelation coefficients describe the relation between contemporaneous matching flows within a region and its neighboring regions. Contemporaneous matches in neighboring regions are therefore not a valid explanatory variable for the efficiency of the matching process in a given region. Moreover, from a conceptual point of view, all relevant and available variables have been included in the estimated specification, which resembles closely the specifications used in the literature. Spatial dependen-

cies in job creation are to a certain extent accounted for by including also 
spatially lagged explanatory variables. Finally, regressing spatial correlation patterns on matching efficiency would clearly make little sense as there is nothing of the statistical concept of spatial autocorrelation to be explained by the efficiency of the matching process. Nevertheless, the results of this analysis should be interpreted as correlations, rather than causal effects.

The plain values of the Local Moran's I statistic are only meaningful on an ordinal scale. In order to obtain results that have a clearer interpretation, we therefore normalize the values of the statistic obtained for each region by taking the ratio of the statistic of the given region relative to the respective absolute group maximum, instead of using the plain values of the Local Moran's I statistic as explanatory variable. ${ }^{15}$ This way, one obtains values between 0 and 1 , which reflect the extent of spatial dependencies of a given region relative to the region with the strongest regional dependencies in the given decomposition set. The estimated coefficients for the normalized values of the Moran's I statistic can therefore be interpreted as elasticities. Using the plain values of Local Moran's $I$ statistics directly as regressors instead of the normalized values does not affect our qualitative results. ${ }^{16}$ In order to have a reasonably flexible specification, we additionally include a squared term of normalized Local Moran's $I$ as regressor.

Table 4 contains the results of this analysis. Specifications (1) and (2) deliver estimates of the correlation between matching efficiency and the spa-

\footnotetext{
${ }^{15}$ In other words, we divide the respective value of the Local Moran's $I$ statistic of cluster regions by the maximum Local Moran's $I$ for the given subsample, and the value of hot spot regions by the (absolute value of the) minimum Local Moran's $I$. Note that the division by the absolute maximum implies that the normalized Local Moran's $I$ values remain positive for cluster regions, and negative for hot spot regions.

${ }^{16}$ Results are available from the authors upon request.
} 
tial correlation structure of a region unconditional as well as conditional on region and year fixed effects. While there seems no unconditional correlation, spatial autocorrelation of matches exhibits a significantly positive, but small effect on matching efficiency when two-way fixed effects are taken into account. However, as indicated before when discussing hot spots and clusters, this may not be a very sensible analysis to do, since positive and negative spatial autocorrelation have distinct implications for the job search process, and since the absolute level of correlation might also be relevant. Moreover, major changes like German reunification might have profoundly changed the matching process in West German regions.

In order to shed more light on these issues affecting the correlation between spatial dependencies and matching efficiency, we split the sample in two ways. We separately consider regions with positive spatial autocorrelation in matches (clusters) in specifications (3) - (6), and regions with negative spatial autocorrelation (hot spots) in specifications (7) - (10). We further specify the analysis by decomposing the samples of clusters and hot spots into subsamples reflecting pre-reunification and post-reunification period. When regressing matching efficiency only on a constant and a linear and squared term of normalized Local Moran's I in the clusters-sample, spatial correlation has a significant negative effect on efficiency. This effect seems to be non-linear, that is, becomes less pronounced the stronger the correlation due to the implied convexity of the relationship. Both these effects survive when controlling for region and time fixed effects, and regardless of considering the entire time period, or pre- and post-reunification periods separately. Indeed, it turns out that the detrimental effect of positive spatial autocorrelation in hiring flows in cluster regions is stronger after reunification than 
before. On top of that, the convexity is stronger in the subsample for the later years, as well. This is an indication both for crowding externalities and cross-regional competition for jobs in general, but also for an increased competition after the shock of reunification, which led to a substantial inflow of workers from Eastern Germany. These estimated effects of spatial dependencies on the matching efficiency of clusters are economically significant. When only considering the linear part of the estimation, the fact that a region shows a one percent stronger positive autocorrelation with neighboring regions relative to the maximum observed positive autocorrelation within the sample lowers the matching efficiency for that region by around 0.20 to 0.30 percent. The effect is only smaller during the pre-reunification period. ${ }^{17}$

When considering the subsample of regions with negative spatial dependencies in hiring flows, hot spots, a similar picture emerges. First, the relationship between spatial correlation and matching efficiency is positive, which implies that larger (more negative) spatial autocorrelation in matches implies a lower efficiency of the matching process. ${ }^{18}$ In the sample that pools all years, this negative relationship is non-linear and less pronounced the stronger the spatial correlation, as seen from the negative coefficient for the squared term in specification (8). When estimated separately for the pre- and post-reunification periods, the relationship is approximately linear, however. Moreover, the negative effect of spatial dependencies seems to have somewhat weakened in the aftermath of reunification. Interestingly,

\footnotetext{
${ }^{17}$ The effects of the squared term are quantitatively of second order since the normalized values of Moran's $I$ are fractions.

${ }^{18}$ The reverse sign is explained by the negative values of normalized Local Moran's $I$ in hot spots.
} 
the predictive power of the model is substantially higher during the post reunification period, regardless of the subsample considered. This could be an indication of the fact that regional labor markets indeed became more integrated after reunification, implying a larger impact of mobility, and more pronounced search externalities. Also quantitatively, the effects of spatial dependencies among hot spots on the efficiency of the matching process are significant. The linear part of the estimation reveals an about 0.10 to 0.20 percent lower matching efficiency of hot spots when a region shows a one percent stronger negative autocorrelation with neighboring regions relative to the hot spot with the strongest spatial autocorrelation. What is also striking is that the efficiency decreasing effect of spatial dependencies is of about the same size in both the clusters and the hot spots samples.

These results illustrate that the spatial structure of the matching process is rather complex. The more correlated the hiring process is across a group of neighboring regions, that is, the more procyclical or countercyclical the job creation processes are in these regions, the less efficient the job creation process is as a whole. However, given the completely different context of spatial dependencies among clusters and hot spots, it is likely that also the mechanism linking spatial dependencies to matching efficiency is totally different for hot spots and clusters. The negative effect in the sample of hot spots can be directly interpreted as the result of crowding externalities: the fewer matches are created in one region as opposed to a neighboring region in the same period, the more people will try to move to that region. That is, if there are many new jobs created in metropolitan hot spot regions, workers from all neighboring regions, where few jobs are created, move into the metropolitan areas, and vice versa, creating significant externalities. 
Apparently, these externalities induced by such mobility and search behavior slow down the matching process. In clusters of regions with synchronous job creation processes, the efficiency of the matching process also decreases with the extent of the spatial dependencies. Here, however, it is likely that cyclical effects are pronounced by the fact that regions exhibit similar industry structure, and therefore similar hiring patterns. In other words, if a cluster of regions exhibits vivid hiring activity, the search process is slowed down by the competition for workers, while, if the hiring activity is modest in a cluster, matches take a long time to materialize. Stronger autocorrelation and its detrimental effect on the efficiency of the matching process might therefore indicate crowding externalities between job searchers in hot spots and crowding externalities between recruiting firms in clusters. From a policy point of view, however, this implies that different policy measures are called for when attempting to improve the efficiency of the matching process in different regions.

\section{Conclusion}

This paper analyzes for the first time the efficiency of the matching process between unemployed job searchers and vacancies in West-Germany. Using a panel of 117 labor market regions over the period 1980-1997, we estimate a stochastic frontier model of the matching function, which delivers similar parameters for the matching elasticities as earlier comparable studies that did not take inefficiencies explicitly into account. The results of the efficiency analysis indicate beneficial efficiency effects of young labor market participants, and labor markets for high and low skilled workers, while the 
opposite is true for old workers and workers with intermediate skill levels. Overall, the results indicate that the matching process in West-Germany seems to have become more efficient since reunification took place.

Regions vary substantially with respect to the matching efficiency of their labor markets. While some regions achieve a degree of efficiency of more than 90 percent, others utilize only 30 percent of their matching potential. This efficiency pattern and the implied ranking of regions is surprisingly stable over the observation period. As an obvious candidate for explaining these patterns, we investigate the spatial dependencies in job creation across regions. Also here, we find substantial variation, with some clusters of neighboring regions exhibiting highly positively correlated flows of newly created jobs, and other regions, so-called hot spots, whose job creation is highly negatively correlated with that of the regions next to them. On top of that, also these patterns exhibit considerable stability over the observation period. When regressing regional matching efficiency on spatial correlation measures, high spatial autocorrelation is associated with a relatively low matching efficiency, and hence a lengthy matching process. Moreover, this relationship between efficiency and spatial matching dependencies appears to be slightly convex.

Our analysis provides a first step towards understanding the determinants of the efficiency of the matching process. Moreover, our results disclose a strong relationship between spatial dependencies in job creation and the efficiency of job creation that has not been shown before, and that we think reflects search frictions. It is questionable, whether policies aimed to improve the matching process can be effective as long as they do not attenuate the effects of spatial dependencies. In particular, our reduced form results 
show that a strong negative as well as a strong positive autocorrelation with neighboring regions leads to a reduced matching efficiency. The driving mechanisms between spatial autocorrelation in job creation activity and matching efficiency seem to be fundamentally different between hot spots and clusters. Potentially, the crowding externalities between job searchers are reflected in lower matching efficiencies in hot spots, while in clusters the similar industry structure reflects crowding externalities between recruiting firms. Policies aimed at improving matching efficiencies should therefore employ different measures in hot spots than in clusters. From a conceptual point of view our analysis on the level of regions complements studies using data on the aggregate or on the individual level, since such studies have little to say about regional differences. Regional variation in the matching process, and the correlation between the matching efficiency and spatial dependencies in job creation, which we analyze in this paper, have not been investigated before. These issues are particularly important when it comes to evaluate the appropriateness of policy measures, however. By pointing out the substantial regional variation in the matching process as well as the role of spatial dependencies for the speed with which job seekers and vacancies match, our study constitutes a first step towards the understanding of the channels and driving mechanisms behind the relationship between matching efficiency and spatial autocorrelation patterns, but more research is certainly needed. 


\section{References}

Anselin, L. (1995): "Local Indicators of Spatial Association - LISA," Geographical Analysis, 27(2), 93-115.

Battese, G. E., And T. J. Coelli (1995): "A Model for Technical Inefficiency Effects in a Stochastic Frontier Production Function for Panel Data," Empirical Economics, 20, 325-332.

Bender, S., A. HaAs, and C. Klose (2000): "The IAB Employment Subsample 1975-1995," Journal of Applied Social Science Studies, 120(2), 649-662.

Broersma, L., and J. Van Ours (1999): "Job Searchers, Job Matches, and the Elasticity of Matching," Labour Economics, 6(1), 77-93.

Burgess, S., And S. Profit (2001): "Externalities in the Matching of Workers and Firms in Britain," Labour Economics, 8(3), 313-333.

Destefanis, S., And R. Fonseca (2004): "Labour Market Reform and the Beveridge Curve in Italy Throughout the 1990s: A Stochastic Frontier Approach," Paper Presented at EALE Meetings 2004, Lisbon.

EnTorf, H. (1998): Mismatch Explanations of European Unemployment: A Critical Evaluation. Springer Verlag, Berlin.

Fahr, R., And U. Sunde (2002): "Employment Status, Endogenous Regional Mobility, and Spatial Dependencies in Labor Markets," IZA Discussion Paper, 521.

(2004): "Occupational job creation: patterns and implications," Oxford Economic Papers, 56(3), 407-435.

Gorter, C., And J. Van Ours (1994): "Matching Unemployment and Vacancies in Regional Labor Markets: An Empirical Analysis for the Netherlands," Papers in Regional Science, 73(2), 153-167.

Gross, D. (1997): "Aggregate Job Matching and Returns to Scale in Germany," Economics Letters, 56(2), 243-248.

Ibourk, A., B. Maillard, S. Perelman, and H. R. Sneessens (2004): "Aggregate Matching Efficiency: A Stochastic Production Frontier Approach, France 1990-1994," Empirica, 31, 1-25.

Ilmakunnas, P., And H. Pesola (2003): "Regional Labour Market Matching Functions and Efficiency Analysis," Labour, 17(3), 413-437. 
Karagiannis, G., P. Midmore, and V. Tzouvelekas (2002): "Separating Technical Change From Time-Varying Technical Inefficiency in the Absence of Distributional Assumptions," Journal of Productivity Analysis, 18, 23-38.

Petrongolo, B., and C. Pissarides (2001): "Looking Into the Black Box: A Survey of the Matching Function," Journal of Economic Literature, 39(2), 390-431.

WArren, R. S. (1991): "The Estimation of Frictional Unemployment: A Stochastic Frontier Approach," Review of Economics and Statistics, 73(2), $373-377$. 


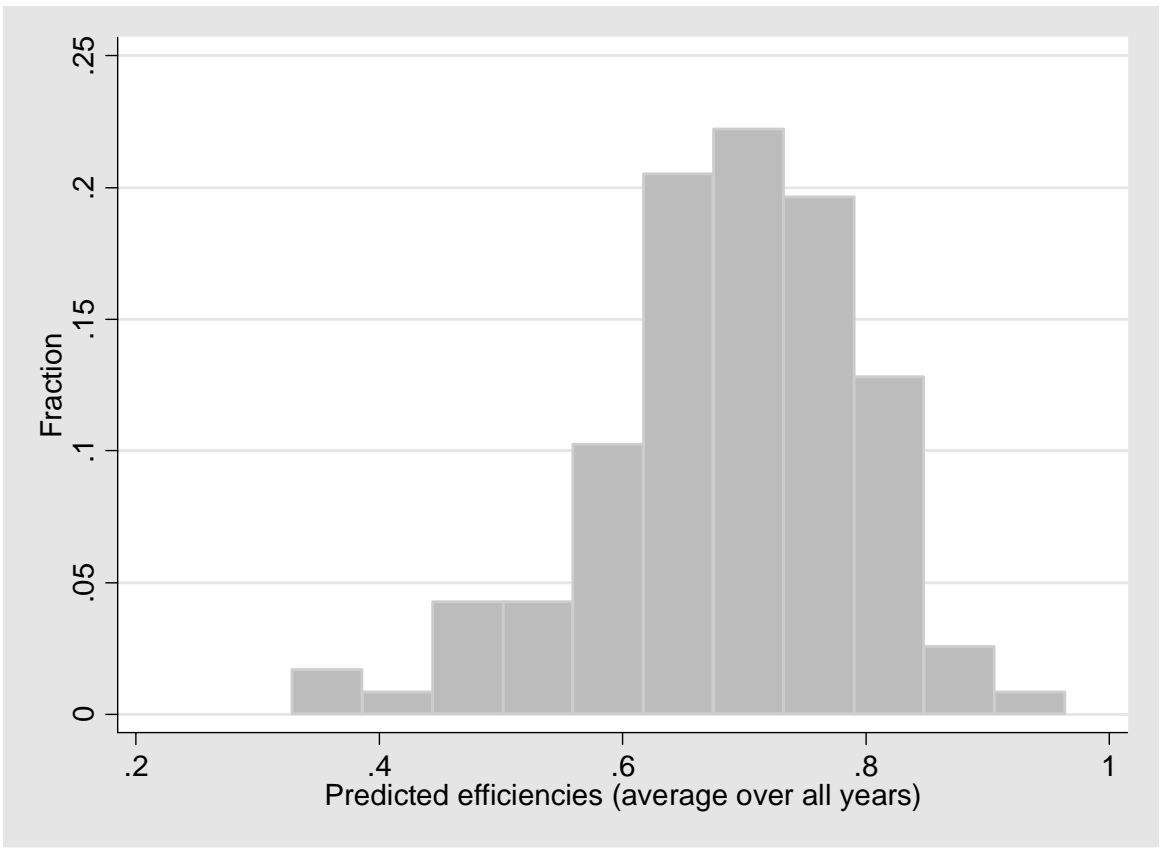

Figure 1: Frequency Distribution of Matching Efficiencies in Regions (computed using predicted values and averaged over period 1980-1997 for every region) 
Table 1: Stochastic Frontier Estimates

\begin{tabular}{|c|c|c|}
\hline & \multicolumn{2}{|c|}{$\begin{array}{c}\text { Dependent variable: logarithm of } \\
\text { hirings }\end{array}$} \\
\hline & (1) & (2) \\
\hline $\ln U$ & 0.540 & 0.542 \\
\hline (Local UE) & $(0.019)$ & $(0.018)$ \\
\hline $\ln V$ & 0.336 & 0.335 \\
\hline (Local reg. vacancies) & $(0.013)$ & $(0.013)$ \\
\hline $\ln W U$ & -0.169 & -0.169 \\
\hline (UE neighbor. regions) & $(0.014)$ & $(0.014)$ \\
\hline $\ln \underline{\mathbf{W}} \boldsymbol{U} \times 10^{2}$ & 0.114 & 0.116 \\
\hline $\begin{array}{l}\text { (UE non-neighbor. } \\
\text { regions) }\end{array}$ & $(0.041)$ & $(0.044)$ \\
\hline constant & $\begin{array}{c}4.567 \\
(0.156)\end{array}$ & $\begin{array}{c}4.548 \\
(0.145)\end{array}$ \\
\hline Efficiency coefficients & & \\
\hline constant & $\begin{array}{l}-1.377 \\
(0.342)\end{array}$ & $\begin{array}{l}-1.360 \\
(0.354)\end{array}$ \\
\hline fraction young $(<25)$ & $\begin{array}{c}2.156 \\
(0.375)\end{array}$ & $\begin{array}{c}2.224 \\
(0.475)\end{array}$ \\
\hline fraction old $(>50)$ & $\begin{array}{l}-0.404 \\
(0.545)\end{array}$ & $\begin{array}{l}-0.354 \\
(0.661)\end{array}$ \\
\hline fraction low education & $\begin{array}{c}0.505 \\
(0.270)\end{array}$ & $\begin{array}{c}0.520 \\
(0.285)\end{array}$ \\
\hline fraction high education & $\begin{array}{c}6.384 \\
(0.766)\end{array}$ & $\begin{array}{c}6.514 \\
(0.814)\end{array}$ \\
\hline tightness $(\ln (\mathrm{V} / \mathrm{U}))$ & $\begin{array}{c}0.073 \\
(0.023)\end{array}$ & $\begin{array}{c}0.071 \\
(0.024)\end{array}$ \\
\hline $\ln U$ & 0.067 & 0.065 \\
\hline (Local UE) & $(0.027)$ & $(0.025)$ \\
\hline time trend & $\begin{array}{c}0.107 \\
(0.051)\end{array}$ & $\begin{array}{l}-0.039 \\
(0.006)\end{array}$ \\
\hline$(\text { time trend })^{2} \times 10^{2}$ & $\begin{array}{l}-0.092 \\
(0.049)\end{array}$ & - \\
\hline $\begin{array}{l}\text { After re-unification period } \\
(\text { yes }=1)\end{array}$ & $\begin{array}{c}0.100 \\
(0.037)\end{array}$ & $\begin{array}{c}0.250 \\
(0.127)\end{array}$ \\
\hline $\begin{array}{l}\text { Interaction: time trend } \mathrm{x} \\
\text { re-unification-indicator }\end{array}$ & - & $\begin{array}{l}-0.014 \\
(0.010)\end{array}$ \\
\hline$\sigma^{2}$ & $\begin{array}{c}0.090 \\
(0.006)\end{array}$ & $\begin{array}{c}0.090 \\
(0.006)\end{array}$ \\
\hline$\gamma$ & $\begin{array}{c}0.760 \\
(0.034)\end{array}$ & $\begin{array}{c}0.757 \\
(0.017)\end{array}$ \\
\hline Log (likelihood) & -110.680 & -111.294 \\
\hline $\mathrm{N}$ & 2106 & 2106 \\
\hline
\end{tabular}


Table 2: Regions with Highest and Lowest Efficiency of the Matching Process

\begin{tabular}{l|clc|clc|clc}
\hline & \multicolumn{3}{|c|}{ Avg. 1980-1997 } & \multicolumn{3}{c|}{ Avg. 1980-1989 } & \multicolumn{3}{c}{ Avg. 1990-1997 } \\
& region & eff. & region & eff. & region & eff. \\
\hline Rank 1 & 112 & Munich & 0.906 & 58 & Marburg & 0.927 & 112 & Munich & 0.883 \\
Rank 2 & 33 & Düsseldorf & 0.883 & 112 & Munich & 0.924 & 33 & Düsseldorf & 0.852 \\
Rank 3 & 51 & Frankfurt & 0.876 & 85 & Ravensburg & 0.919 & 51 & Frankfurt & 0.843 \\
Rank 4 & 2 & Hamburg & 0.857 & 19 & Nordhorn & 0.914 & 2 & Hamburg & 0.812 \\
Rank 5 & 5 & Lübeck & 0.846 & 5 & Lübeck & 0.911 & 68 & Neuwied & 0.796 \\
\hline Rank 113 & 10 & Goslar & 0.454 & 64 & Landau & 0.512 & 9 & Emden & 0.407 \\
Rank 114 & 64 & Landau & 0.452 & 10 & Goslar & 0.489 & 64 & Landau & 0.377 \\
Rank 115 & 17 & Lüneburg & 0.387 & 16 & Leer & 0.440 & 17 & Lüneburg & 0.339 \\
Rank 116 & 16 & Leer & 0.384 & 17 & Lüneburg & 0.426 & 16 & Leer & 0.315 \\
Rank 117 & 8 & Celle & 0.328 & 8 & Celle & 0.357 & 8 & Celle & 0.293 \\
\hline
\end{tabular}

Note: Region numbers refer to the regions as listed in Appendix. Efficiency estimates refer to predictions of TE following the estimation of specification (1) in Table 1.

Table 3: Regions with Highest Spatial Dependencies in the Matching Process

\begin{tabular}{|c|c|c|c|}
\hline \multicolumn{2}{|c|}{$\begin{array}{l}\text { significant positive autocorrelation in hirings } \\
\text { CLUSTERS }\end{array}$} & \multicolumn{2}{|c|}{$\begin{array}{c}\text { significant negative autocorrelation in hirings } \\
\text { HOT SPOTS }\end{array}$} \\
\hline region number & region & region number & region \\
\hline 5 & Lübeck & 2 & Hamburg \\
\hline 16 & Leer & 3 & Heide \\
\hline 33 & Düsseldorf & 7 & Bremen \\
\hline 34 & Duisburg & 13 & Hannover \\
\hline 35 & Essen & 17 & Lüneburg \\
\hline 36 & Gelsenkirchen & 32 & Düren \\
\hline 39 & Cologne & 51 & Frankfurt \\
\hline 42 & Mönchengladbach & 89 & Stuttgart \\
\hline 43 & Münster & 99 & Nuremberg \\
\hline 56 & Korbach & 112 & Munich \\
\hline
\end{tabular}


Table 4: Empirical Results for the Relationship between Matching Efficiency and Spatial Dependencies

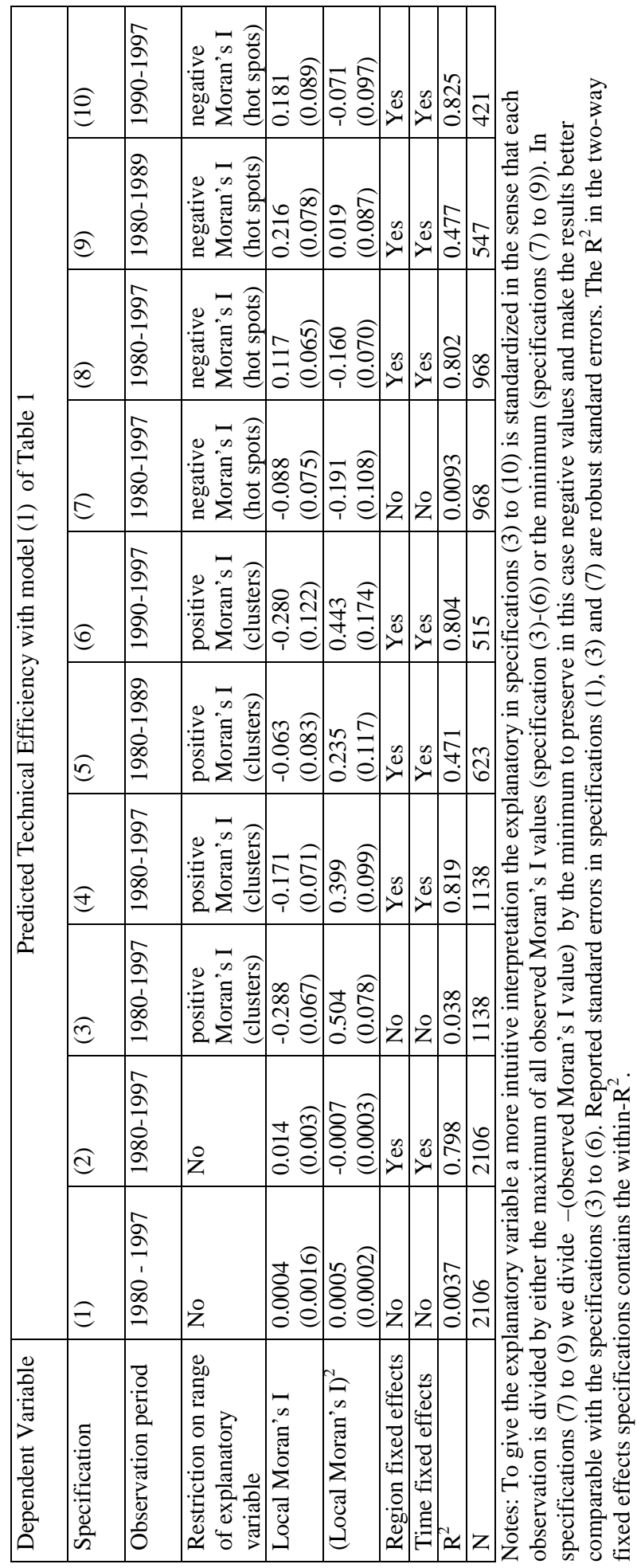


Table 5: Regional Labor Markets in West Germany

\begin{tabular}{|c|c|c|c|}
\hline $\begin{array}{r}\text { Region } \\
\text { number }\end{array}$ & Region & $\begin{array}{r}\text { Region } \\
\text { number }\end{array}$ & Region \\
\hline 1 & Flensburg & 64 & Landau \\
\hline & Hamburg, incl. Bad Oldesloe, & 65 & Ludwigshafen \\
\hline 2 & Elmshorn, Stade & 66 & Mainz \\
\hline 3 & Heide & 67 & Montabaur \\
\hline 4 & Kiel incl. Neumünster & 68 & Neuwied \\
\hline 5 & Lübeck & 69 & Pirmasens \\
\hline 6 & Braunschweig & & Saarbrücken, incl. Neunkirchen, \\
\hline 7 & Bremen, incl. Bremerhaven, Verden & 70 & Saarlouis \\
\hline 8 & Celle & 71 & Trier \\
\hline 9 & Emden & 72 & Aalen \\
\hline 10 & Goslar & 73 & Balingen \\
\hline 11 & Göttingen & 74 & Freiburg \\
\hline 12 & Hameln & 75 & Heidelberg \\
\hline 13 & Hannover & 76 & Heilbronn \\
\hline 14 & Helmstedt & 77 & Karlsruhe \\
\hline 15 & Hildesheim & 78 & Konstanz \\
\hline 16 & Leer & 79 & Lörrach \\
\hline 17 & Lüneburg & 80 & Mannheim \\
\hline 18 & Nienburg & 81 & Nagold \\
\hline 19 & Nordhorn & 82 & Offenburg \\
\hline 20 & Oldenburg & 83 & Pforzheim \\
\hline 21 & Osnabrück & 84 & Rastatt \\
\hline 22 & Uelzen & 85 & Ravensburg \\
\hline 23 & Vechta & 86 & Reutlingen \\
\hline 24 & Wilhelmshaven & 87 & Rottweil \\
\hline 25 & Aachen & 88 & Schwäbisch Hall \\
\hline 26 & Bergisch Gladbach & & Stuttgart, incl. Göppingen, \\
\hline 27 & Bielefeld, incl. Herford & 89 & Ludwigsburg, Waiblingen \\
\hline 28 & Bochum & 90 & Tauberbischofsheim \\
\hline 29 & Bonn & 91 & Ulm \\
\hline 30 & Detmold & 92 & Villingen-Schwenningen \\
\hline 31 & Dortmund, incl. Hamm & 93 & Ansbach \\
\hline 32 & Düren & 94 & Aschaffenburg \\
\hline 33 & Düsseldorf & 95 & Bamberg \\
\hline 34 & Duisburg., incl. Oberhausen, Wesel & 96 & Bayreuth \\
\hline 35 & Essen & 97 & Coburg \\
\hline 36 & Gelsenkirchen, incl. Recklinghausen & 98 & Hof \\
\hline 37 & Hagen & 99 & Nürnberg, incl. Weissenburg \\
\hline 38 & Iserlohn & 100 & Regensburg \\
\hline 39 & Köln, incl. Brühl & 101 & Schwandorf \\
\hline 40 & Krefeld & 102 & Schweinfurt \\
\hline 41 & Meschede & 103 & Weiden \\
\hline 42 & Mönchengladbach & 104 & Würzburg \\
\hline 43 & Münster, incl. Ahlen, Coesfeld & 105 & Augsburg \\
\hline 44 & Paderborn & 106 & Deggendorf \\
\hline 45 & Rheine & 107 & Donauwörth \\
\hline 46 & Siegen & 108 & Ingolstadt \\
\hline 47 & Soest & 109 & Kempten \\
\hline 48 & Wuppertal, incl. Solingen & 110 & Landshut \\
\hline 49 & Bad Hersfeld & 111 & Memmingen \\
\hline 50 & Darmstadt & 112 & München, incl. Freising \\
\hline 51 & Frankfurt, incl. Offenbach & 113 & Passau \\
\hline 52 & Fulda & 114 & Pfarrkirchen \\
\hline 53 & Gießen & 115 & Rosenheim \\
\hline 54 & Hanau & 116 & Traunstein \\
\hline 55 & Kassel & 117 & Weilheim \\
\hline 56 & Korbach & & \\
\hline 57 & Limburg & & \\
\hline 58 & Marburg & & \\
\hline 59 & Wetzlar & & \\
\hline 60 & Wiesbaden & & \\
\hline 61 & Bad Kreuznach & & \\
\hline 62 & Kaiserslauten & & \\
\hline 63 & Koblenz, incl. Mayen & & \\
\hline
\end{tabular}




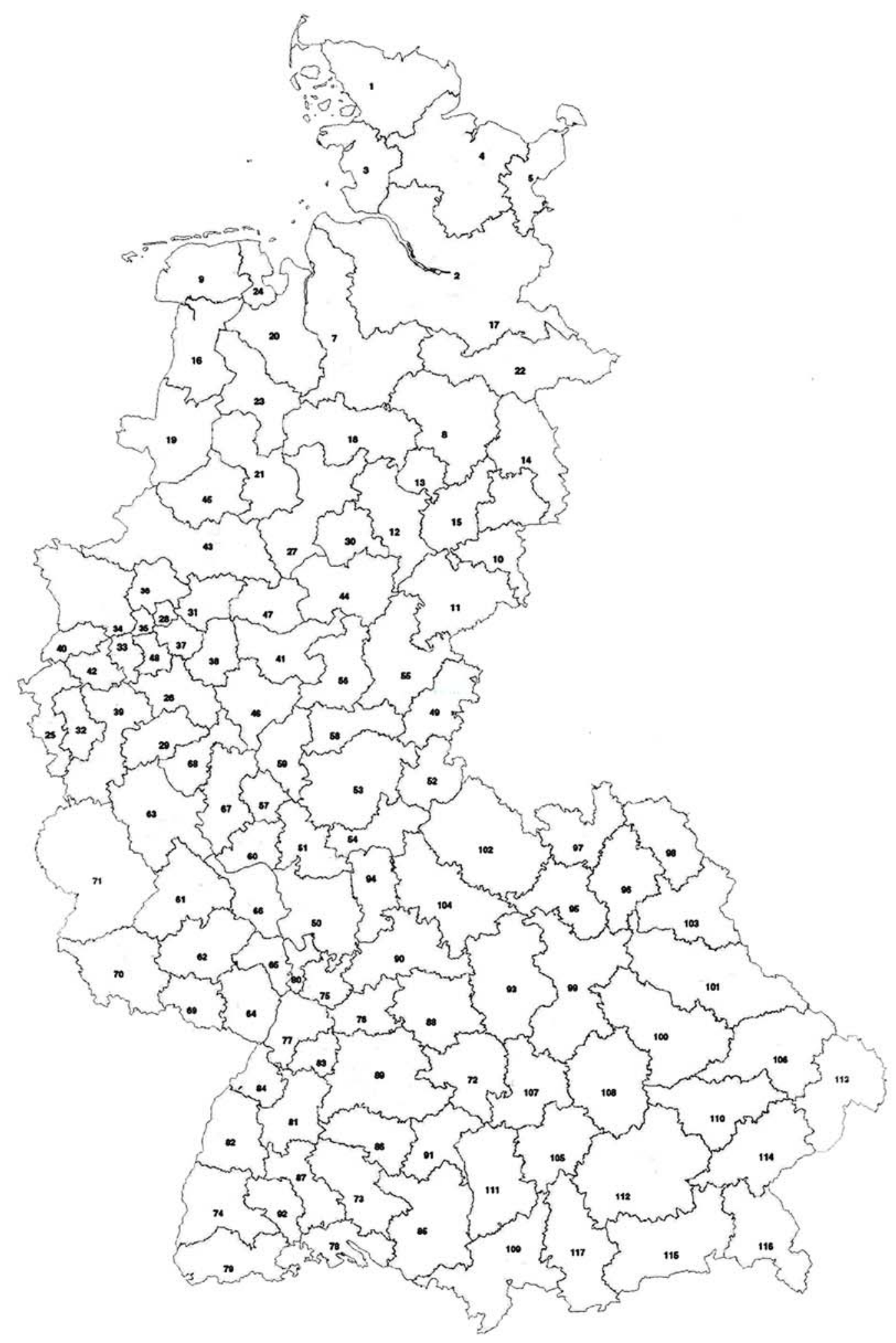

31

Figure 2: Regional Labor Markets in West Germany 